\title{
Covid-19 Impact on Environment
}

\author{
Muhammad Kashan Javed ${ }^{1}$, Dr. Sumbal Javaid ${ }^{2} \&$ Dr. Anam Javaid ${ }^{3}$ \\ ${ }^{1}$ Institute of Molecular Biology and Biotechnology, Baha Uddin Zakariya University, Multan, Pakistan. \\ ${ }^{2}$ Nishtar Medical University and Hospital, Multan, Pakistan. \\ ${ }^{3}$ Women University Multan, Pakistan.
}

DOI: http://doi.org/10.46382/MJBAS.2020.4404

Copyright: (02020 Muhammad Kashan Javed et al. This is an open access article distributed under the terms of the Creative Commons Attribution License, which permits unrestricted use, distribution, and reproduction in any medium, provided the original author and source are credited.

This research aims to highlight the positive impact of COVID-19 on Environment. This research start by planning the questionnaire with the help of google forms which consist of 7 different questions related to environment with only two options YES or NO and then circulated it to 555 folks via a two big platforms like G-Mail and Facebook in order to get maximum responses and we got 211 comebacks. The response rate of this survey is $38 \%$. To know the impact of COVID-19 on Surrounding, Statistical Analysis has been done via percentage analysis as well as several types of charts. This research comes to conclude that majority of the folks notice lots of positive impacts of covid-19 on climate as well as on environment. They notice heavy reduction in noise pollution, air pollution etc., and know that lockdown is blessing for ozone layer as well as for climate and environment. As lockdown gives lots of negative impacts on other things but for environment, this lockdown is not less than a blessing.

\section{Introduction}

Today maximum countries around the world has been shut down just because of Corona Virus Disease 2019(COVID-19) [1].Though this virus disturb everything and had a negative effect around the world but on the other hand there are several positive things has been done because of COVID-19 and this research has been carried out to highlight the positive things which happens just because of this virus [2]. We know that the pollution is one of the biggest problems and it was continually increasing day by days in the past years like air pollution, noise pollution, water pollution etc. and this pollution increase just because of human activities [3]. But in 2020 as corona shutdown the maximum countries, the big fall in the increasing line of pollution has been noticed and this fall happened because of banned in human activities, we can take the example of ozone layer which is important for us because ozone layer protect us from the harmful rays of sun and in previous years it has been depleting vastly just because of heavy release of smoke from the different types of vehicles [4]. But a good thing happened because of lockdown, people raise the slogan of stay home and stay safe and the use of vehicles become less and the Filling of ozone layer start rapidly and now a lot of layer has been filled which is the positive sign for us [5]. Similarly, we can see the big reduce in noise pollution as well and as lots of industries stop just coz of this pandemic, Water pollution has been declining [6]. Now, it seems like that humans are more lethal for environment as compared to COVID-19 Pandemic [7-10].

\section{Objective}

This research aims to highlight the positive impact of COVID-19 on Environment.

\section{Methodology}

This research start by planning the questionnaire with the help of google forms which consist of 7 different questions related to environment with only two options YES or NO and then circulated it to 555 folks via a two big 
platforms like G-Mail and Facebook in order to get maximum responses and we got 211 comebacks. The response rate of this survey is $38 \%$.

\section{Statistical Analysis}

To know the impact of COVID-19 on Surrounding, Statistical Analysis has been done via percentage analysis as well as several types of charts.

\section{Results and Discussions}

The outcomes of this survey are listed in the following section.

\section{REDUCTION IN AIR POLLUTION DUE TO COVID-}

19

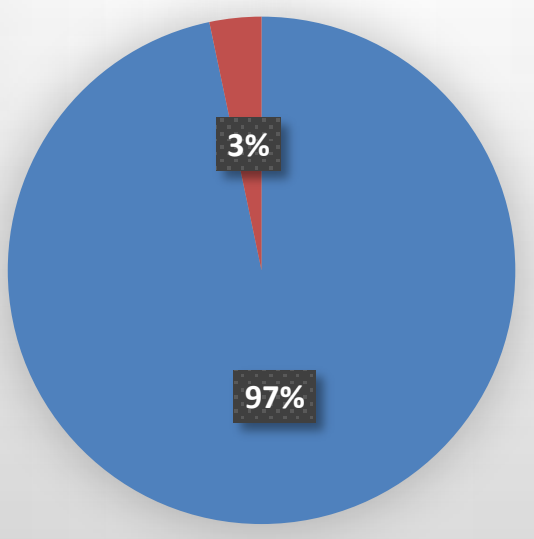

Fig.1. Reduction in Air Pollution due to Covid-19

This chart shows that $97 \%$ folks notice heavy reduction in air pollution and only 3 notice heavy reduction in air pollution and only $3 \%$ thinks that there is no reduction in air pollution.

\section{LESS TRANSPORT USAGE DURING LOCKDOWN}

$120.00 \%$

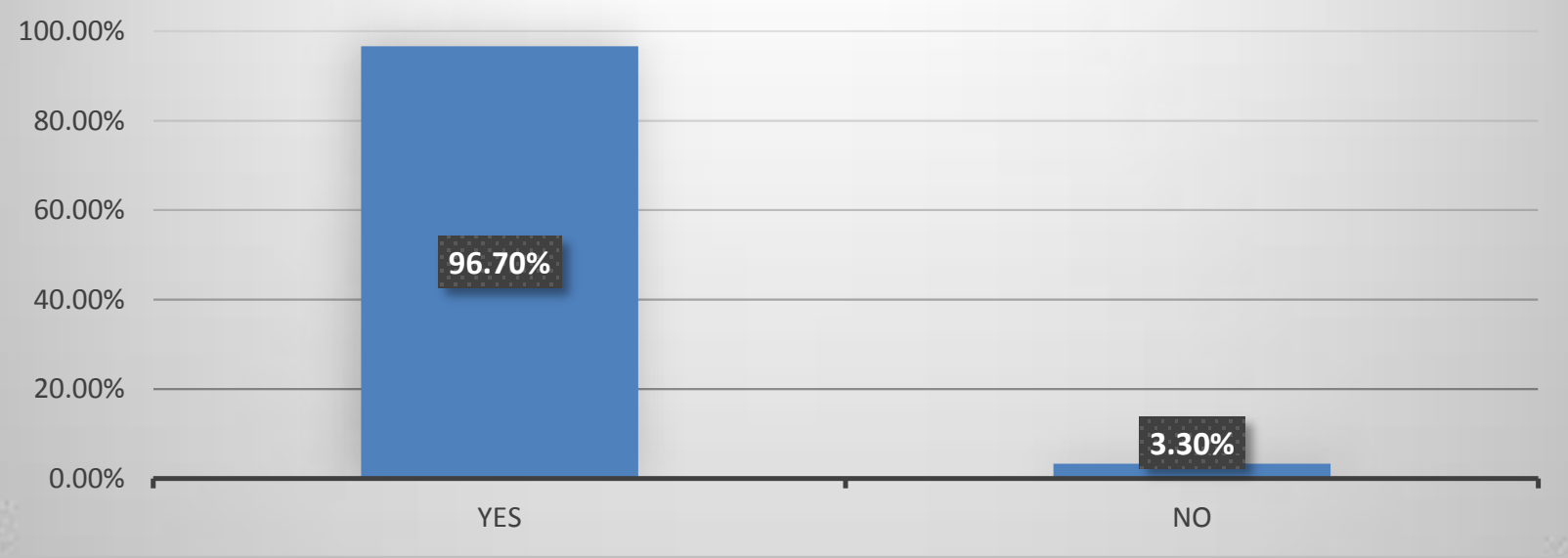

Fig.2. Less Transport Usage during Lockdown 
This graph shows that $96.7 \%$ individuals think that people use less transport during the lockdown.

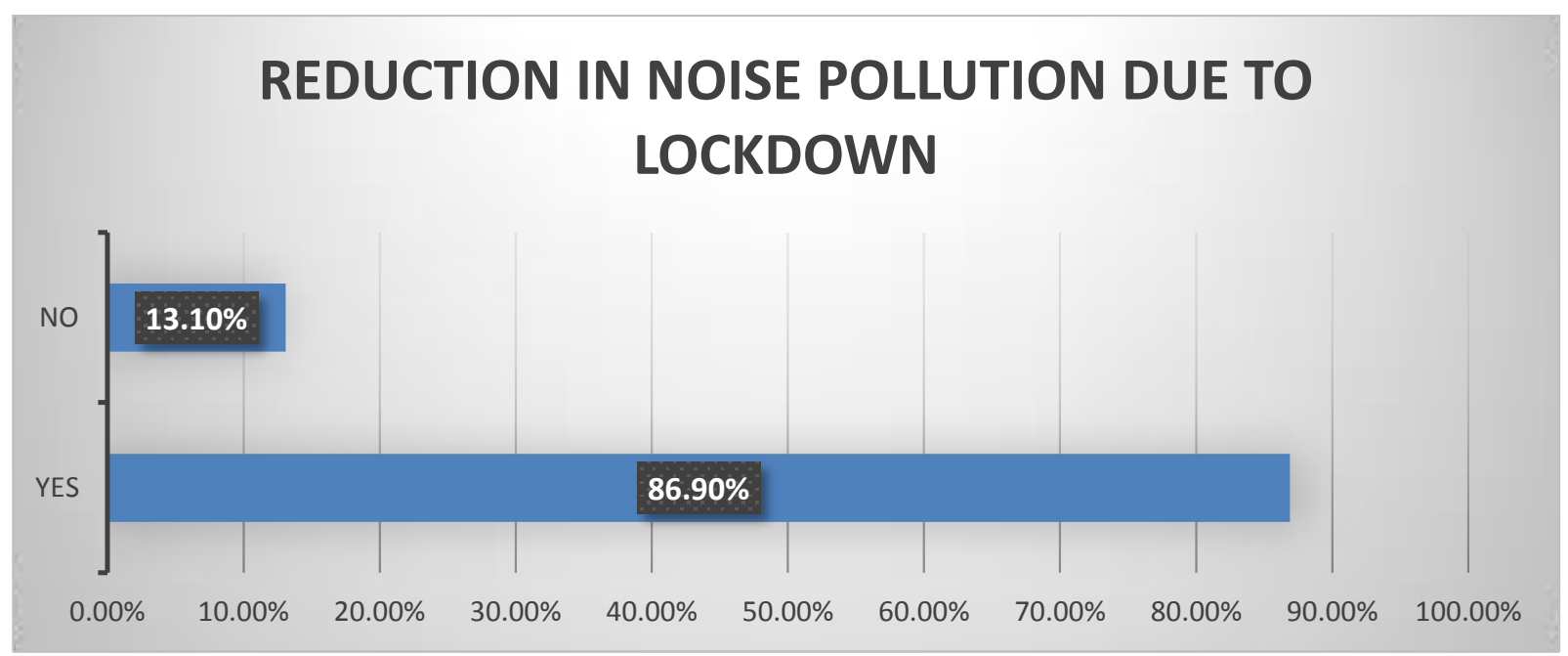

Fig.3. Reduction in Noise Pollution due to Lockdown

This figure shows that $86.9 \%$ persons notice reduction in noise pollution during the shutdown.

\section{POSITIVE CHANGES IN CLIMATE DURING LOCKDOWN}

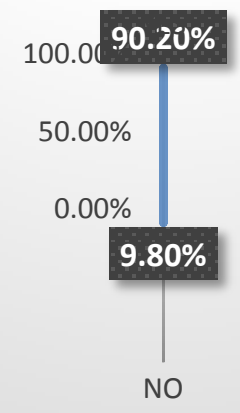

Fig.4. Positive Changes in Climate during Lockdown

This chart shows that $90.2 \%$ folks notice lots of positive impacts in climate during the shutdown.

\section{OZONE LAYER START FILLING FASTER IN 2020}

$100.00 \%$

$80.00 \%$

$60.00 \%$

$40.00 \%$

$20.00 \%$

$0.00 \%$

\section{$90.20 \%$}

Fig.5. Ozone Layer Start Filling Faster in 2020 
This graph shows that $90.2 \%$ individuals know that the ozone layer start filling faster in 2020 as compared to previous years.

\section{EARTH IS BECOMING CLEAN DURING LOCKDOWN}

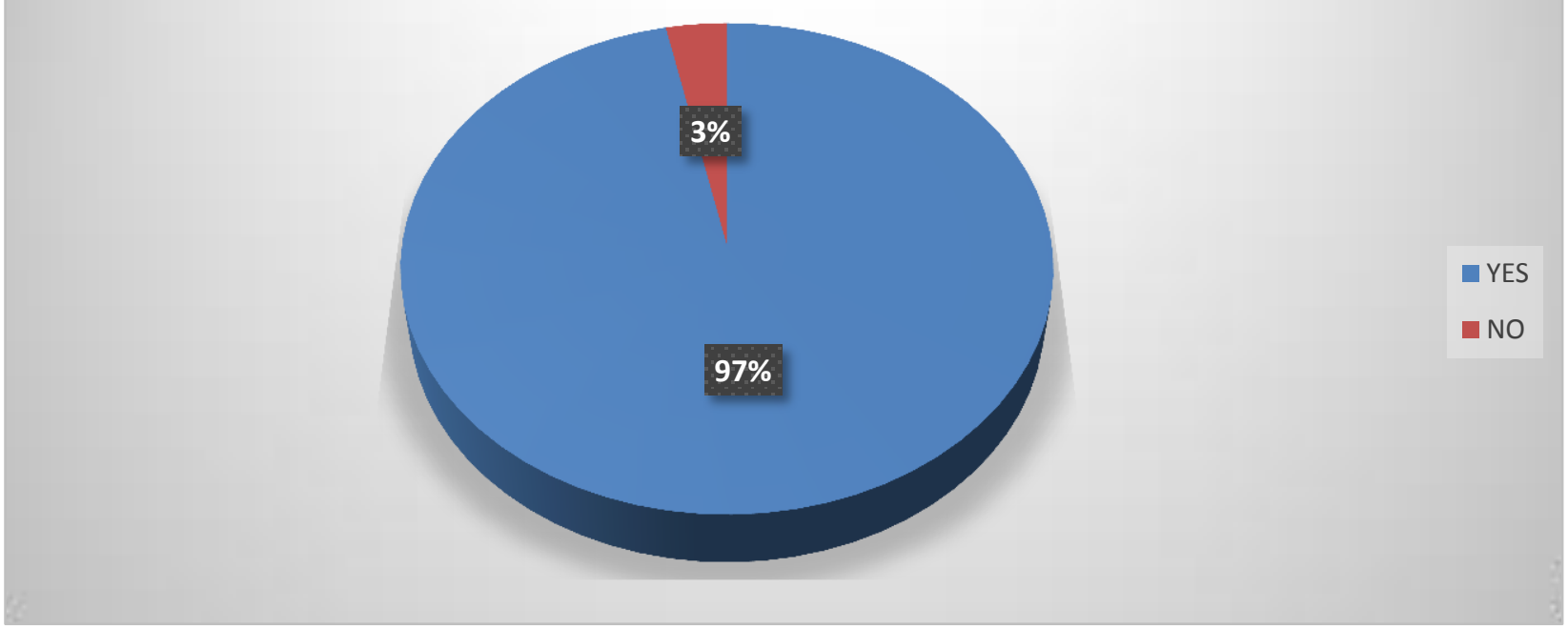

Fig.6. Earth is Becoming Clean during Lockdown

This chart shows that $97 \%$ individuals notice that earth is becoming cleaner during the lockdown.

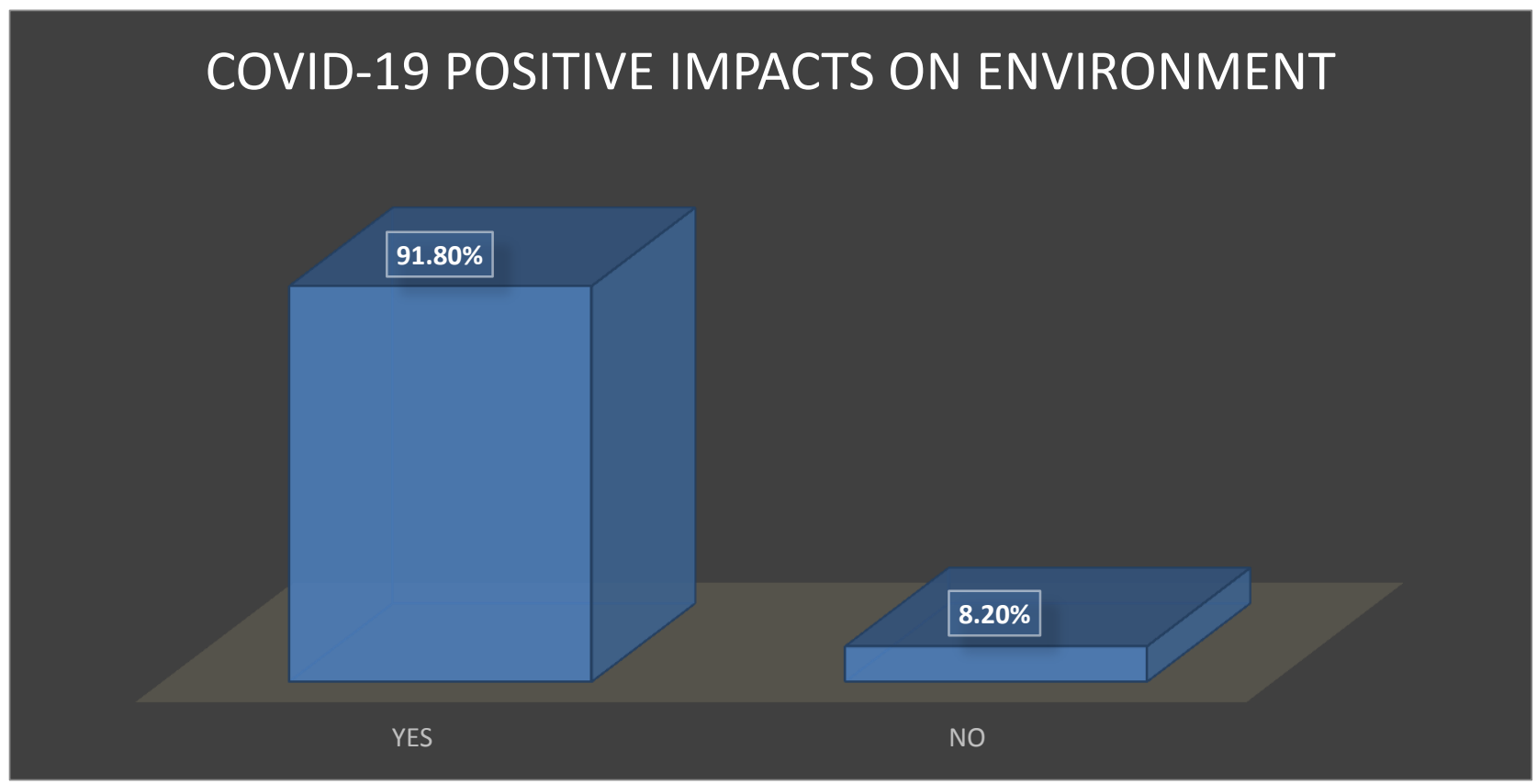

Fig.7. Covid-19 Positive Impacts on Environment

This chart shows that $91.8 \%$ people notice the positive impacts of covid-19 on environment also. They said that environment becoming free from pollution just because of lockdown.

\section{Conclusion}

This research comes to conclude that majority of the folks notice lots of positive impacts of covid-19 on climate as well as on environment. They notice heavy reduction in noise pollution, air pollution etc., and know that lockdown 
is blessing for ozone layer as well as for climate and environment. As lockdown gives lots of negative impacts on other things but for environment, this lockdown is not less than a blessing.

\section{References}

1. Javed, M. K., \& Javaid, S. J. D. A. (2020). Corona Virus Awareness in Pakistan: A Case Study. International Journal of Medical Science in Clinical Research and Review, 3(03,), 256-262.

2. Javaid, S., \& Javaid, M. K. J. D. A. (2020). Survey on Corona Virus: A Case Study in Pakistan. International Journal of Medical Science in Clinical Research and Review, 3(02,), 223-227.

3. Javed, M. K., Bukht, N., \& Javaid, S. (2020). COVID-19 Effect on Poor. International Journal of Medical Science in Clinical Research and Review, 3(03,), 263-268.

4. Javed, M. K., \& Javaid, S. J. D. A. (2020). Corona Virus Awareness in Pakistan: A Case Study. International Journal of Medical Science in Clinical Research and Review, 3(03,), 256-262.

5. Novel, C. P. E. R. E. (2020). The epidemiological characteristics of an outbreak of 2019 novel coronavirus diseases (COVID-19) in China. Zhonghua liu xing bing xue za zhi= Zhonghua liuxingbingxue zazhi, 41(2), 145.

6. Guan, W. J., Ni, Z. Y., Hu, Y., Liang, W. H., Ou, C. Q., He, J. X., ... \& Du, B. (2020). Clinical characteristics of coronavirus disease 2019 in China. New England journal of medicine, 382(18), 1708-1720.

7. Wang, C., Horby, P. W., Hayden, F. G., \& Gao, G. F. (2020). A novel coronavirus outbreak of global health concern. The Lancet, 395(10223), 470-473.

8. Kashif, M., Javed, M. K., \& Pandey, D. (2020). A Surge in Cyber-Crime during COVID-19. Indonesian Journal of Social and Environmental Issues (IJSEI), 1(2), 48-52.

9. Kashif, M., \& Aziz-Ur-Rehman, M. K. J. (2020). Social media addiction due to coronavirus. International Journal of Medical Science in Clinical Research and Review, 3(04), 331-336.

10. Bukht, N., \& Javed, M. K. (2020). Banker's Awareness of Corona Virus. International Journal of Medical Science in Clinical Research and Review, 3(03,), 251-255. 